\title{
Lichenicolins A and B, New Bisnaphthopyrones from an Unidentified Lichenicolous Fungus, Strain LL-RB0668
}

\author{
Haiyin He, Ramunas Bigelis, Hui Y. Yang, Li-Ping Chang, Maya P. Singh
}

Received: September 13, 2005 / Accepted: November 10, 2005

(C) Japan Antibiotics Research Association

\begin{abstract}
Lichenicolous fungus $L L-\mathrm{RB} 0668$ was isolated from a processed lichen thallus on a modified Lilly-Barnett solid medium. Two new bisnaphthopyrone compounds, lichenicolins A (1) and B (2), were isolated from the culture broth of this organism fermented on a rice-based solid medium. These results demonstrate that lichenassociated fungi potentially are a good resource for new bioactive natural products for current screening programs.
\end{abstract}

Keywords lichenicolous, fungus, bisnaphthopyrone, lichenicolins, antibacterial

\section{Introduction}

Though fungi are important sources of therapeutic compounds and have been successfully exploited for the production of new pharmaceuticals, lichen-associated fungi, which make up more than one-fifth of the fungal kingdom [1] are underrepresented in many industrial culture collections [2]. The lichen-associated fungi include lichen-forming fungi (mycosymbionts) growing in symbiosis with algae, as well as lichenicolous fungi growing on the lichen as parasites, commensals or saprobes. This major group of fungi is known to be a source of chemical diversity [3 5]. Lichenicolous fungi are relatively under-collected in most regions of the world outside Europe and collections of such fungi from North America are especially meager [2].

In the process of enhancing our natural products extract

H. He (Corresponding author), R. Bigelis, H. Y. Yang, L.-P. Chang, M. P. Singh: Natural Products Research, Chemical and Screening Sciences, Wyeth 401 N. Middletown Road, Pearl River, NY 10965, U.S.A., E-mail: heh@wyeth.com library to meet the needs of screening programs, we have investigated methods for isolating mycosymbionts and lichenicolous fungi, and examined secondary metabolites produced by these fungi. In this paper we describe the production, isolation, and identification of two new bisnaphthopyrones from a lichenicolous fungus, strain $L L$ RB0668.

\section{Materials and Methods}

\section{Culture Isolation and Identification}

An unidentified crustose lichen was collected from maple tree bark in Fairfield County, Connecticut. Fungal strain $L L$-RB0668 was isolated from the sample after washing of lichen fragments, homogenization, sieving of lichen particles on $149 \mu \mathrm{m}$ and $44 \mu \mathrm{m}$ screens, and then plating on modified Lilly-Barnett medium [6]. This solid medium contained Gelrite solidifying agent, tetracycline, and L-ribitol as the main carbon source.

Fungus $L L$-RB0668 grew on potato dextrose agar as compact, sulcate and leathery colonies. The colonies were light grey (8D1) to reddish grey (8D2) [7], and had a velvety appearance with colorless exudates. The reverse was reddish brown (9F4 to 9E4) with a reddish brown diffusible pigment.

Fungus $L L$-RB0668 was grown on a number of Difco microbiological media (Becton, Dickinson and Company) in attempts to identify the organism. The culture media were Corn Meal Agar, Emerson YpSs Agar, Lima Bean Agar, Malt Extract Agar, Potato Dextrose Agar, Oatmeal Agar, Sabouraud Dextrose Agar, Special Yeast and Mold Agar, and YM Agar. The cultures were examined by light microscopy at a $400 \times$ magnification, but morphological structures that could be used for identification were absent. In addition, analysis of the internal transcribed spacer (ITS) 
region of nuclear ribosomal DNA obtained from this fungus did not reveal close matches with any entries in the GenBank $^{\circledR}$ database.

\section{Fermentation}

Fungal culture $L L-R B 0668$ was plated on Difco potato dextrose agar from a frozen $25 \%$ glycerol stock culture and then incubated at $22^{\circ} \mathrm{C}$. A small agar slice bearing mycelial growth was used to inoculate $50 \mathrm{ml}$ of seed culture in Difco potato dextrose broth in a $250-\mathrm{ml}$ Erlenmeyer flask shaken at $200 \mathrm{rpm}$ at $22^{\circ} \mathrm{C}$ for one week. Scaled-up fermentations were performed in 2.8-liter Fernbach flasks containing $102 \mathrm{~g}$ milled rice and $88 \mathrm{ml}$ of a $0.1 \%$ yeast-extract solution per flask. A total of 3 solid-medium cultures were inoculated with seed and maintained static at $22^{\circ} \mathrm{C}$ for 2 weeks.

\section{Compound Purification}

After the fermentation was completed, the cultures were lyophilized and extracted with methanol (3 liters). The crude extract was loaded onto a Sephadex LH-20 column and eluted with methanol. The combined fraction that contained lichenicolin A (1) and B (2) was evaporated to dryness under reduced pressure. The resulting powder was then purified by repeated chromatography on reversed phase HPLC, using a C18 column (YMC ODS-A, $10 \mu \mathrm{m}$, $30 \times 250 \mathrm{~mm}$ ) and a gradient of $50 \sim 100 \%$ acetonitrile in water containing $0.01 \%$ trifluoroacetic acid to afford lichenicolins A (1, 60.8 $\mathrm{mg})$ and $\mathrm{B}(\mathbf{2}, 2.8 \mathrm{mg})$.

Lichenicolin A (1). $[\alpha]_{\mathrm{D}}+217^{\circ}\left(c=0.3, \mathrm{CHCl}_{3}\right)$; UV $\lambda_{\max }\left(3: 2 \mathrm{MeCN} / \mathrm{H}_{2} \mathrm{O}\right.$, Agilent Diode Array Detector) 222, 268, 364 (sh), $379 \mathrm{~nm}$; HR-FTICRMS (positive) $\mathrm{m} / \mathrm{z}$ $631.1827\left[(\mathrm{M}+\mathrm{H})^{+}, \mathrm{C}_{34} \mathrm{H}_{31} \mathrm{O}_{12}\right.$ requires 631.1810]; ${ }^{1} \mathrm{H}$, ${ }^{13} \mathrm{C}$, and 2-D NMR spectral data are listed in Table 1.

Lichenicolin B (2). UV $\lambda_{\max }\left(3: 2 \mathrm{MeCN} / \mathrm{H}_{2} \mathrm{O}\right.$, Agilent Diode Array Detector) 220, 265, 365 (sh), 376, 440 (sh) $\mathrm{nm}$; HR-FTICRMS (positive) $\mathrm{m} / \mathrm{z} 631.1463\left[(\mathrm{M}+\mathrm{H})^{+}\right.$, $\mathrm{C}_{33} \mathrm{H}_{27} \mathrm{O}_{13}$ requires 631.1446]; ${ }^{1} \mathrm{H}$ and ${ }^{13} \mathrm{C}$ NMR spectral data are listed in Table 2.

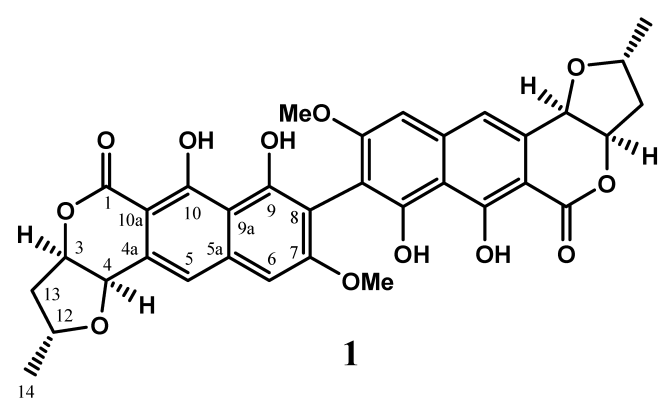

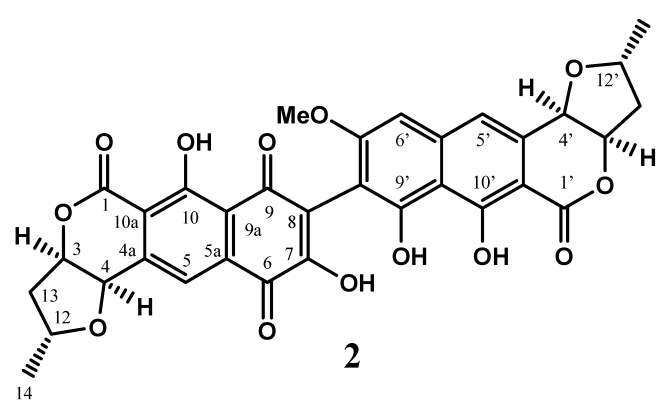<smiles>COc1cc(O)c2c(O)c3c(cc2c1)C[C@@H](C)OC3=O</smiles>

3<smiles>COc1cc2cc3c(c(O)c2c(O)c1-c1c(OC)cc2cc4c(c(O)c2c1O)C(=O)O[C@H](C)C4)C(=O)O[C@H](C)C3</smiles>

4<smiles>COc1cc(O)c2c(O)c3c(cc2c1-c1c(OC)cc(O)c2c(O)c4c(cc12)CC(CC(=O)O)OC4=O)CC(CC(C)=O)OC3=O</smiles>

5<smiles>C[C@H]1Cc2cc3c(c(O)c2C(=O)O1)C(=O)C(C1=C(O)C(=O)c2c(cc4c(c2O)C(=O)O[C@H](C)C4)C1=O)=C(O)C3=O</smiles><smiles>COc1cc(O)c2c(O)c3c(cc2c1-c1c(OC)cc(O)c2c(O)c4c(cc12)CC(C)OC4=O)CC(C)OC3=O</smiles>

7

Fig. 1 Structures of lichenicolins A (1), B (2), and their related compounds. 


\section{Results and Discussion}

The lichenicolous fungus, $L L-$ RB0668, was fermented on a solid medium for two weeks. Purification of the methanol extract of the fermentation medium yielded two new metabolites, designated lichenicolins A and B (Fig. 1). The structure of lichenicolin A was elucidated on the basis of detailed spectroscopic analysis to be bisnaphthopyrone $\mathbf{1}$ and the structure of lichenicolin B was proposed as $\mathbf{2}$ by comparison of its NMR data with those of $\mathbf{1}$ and luteosporin (6).

The molecular formula of lichenicolin A (1) was determined by high resolution Fourier transform ion cyclotron resonance (FTICR) mass spectrometry to be $\mathrm{C}_{34} \mathrm{H}_{30} \mathrm{O}_{12}$. The initial analysis of the ${ }^{13} \mathrm{C}$ NMR spectral data in DMSO- $d_{6}$ indicated the presence of 17 carbon signals, which only accounted for half of the carbons required by the molecular formula. Therefore, compound $\mathbf{1}$ most likely possessed a symmetric dimer structure. The UV spectrum of 1 was consistent with that of a 3,4-dihydro9,10-dihydroxy-7-methoxy-naphtho[2,3-c]pyran-1-one moiety (termed "naphthopyrone"), similar to those contained in compounds semivioxanthin (3) $[8,9]$ and vioxanthin (4) [10]. The ${ }^{1} \mathrm{H}$ NMR spectrum of 1 showed two aromatic singlets at $\delta 7.02$ and 7.37 , and several aliphatic signals, including a methoxyl signal at 3.77 , a methyl doublet at 1.29, 2 methylene signals at 2.53 and 2.06, and 3 methine signals at 5.39, 5.02, and 4.37.

The ${ }^{13} \mathrm{C}$ NMR spectral data (Table 1) assigned by direct $\mathrm{C}-\mathrm{H}$ correlations in an HSQC spectrum and multiple bond correlations in an HMBC spectrum confirmed the presence of the naphthopyrone moiety. The H-6 at $\delta 7.02$ showed strong correlations $\left({ }^{3} J_{\mathrm{CH}}\right)$ to $\mathrm{C}-5,-8$, and $-9 \mathrm{a}$, and weaker correlations $\left({ }^{2} J_{\mathrm{CH}}\right.$ or $\left.{ }^{4} J_{\mathrm{CH}}\right)$ to C-7 and -9 in the HMBC spectrum. The H-5 at $\delta 7.37$ on the other hand displayed strong correlations $\left({ }^{3} J_{\mathrm{CH}}\right)$ to $\mathrm{C}-4,-6,-9 \mathrm{a}$, and $-10 \mathrm{a}$, and weaker correlations $\left({ }^{2} J_{\mathrm{CH}}\right.$ or $\left.{ }^{4} J_{\mathrm{CH}}\right)$ to $\mathrm{C}-1,-4 \mathrm{a},-5 \mathrm{a},-9$, and -10 . The ${ }^{13} \mathrm{C}$ NMR chemical shift data of the carbonyl and the aromatic carbons in $\mathbf{1}$ were almost identical to those in semivioxanthin (3), except that the methine C-8 signal at $\delta$ 99.1 in 3 [8] was replaced by a quaternary carbon signal at 109.02 in 1 . The nature of C-8 was indicative of an $8,8^{\prime}-$ linkage between the two halves of the molecule in compound $\mathbf{1}$. As supporting evidence, the nOes between the H-5 and H-6, and between H-6 and methoxyl group,

Table $1{ }^{1} \mathrm{H}$ and ${ }^{13} \mathrm{C}$ NMR data for lichenicolin A (1) in DMSO- $d_{6}$

\begin{tabular}{|c|c|c|c|c|}
\hline No. & $\begin{array}{c}\delta\left({ }^{1} \mathrm{H}\right) \\
400 \mathrm{MHz}, \text { Mult, } J \text { in } \mathrm{Hz}\end{array}$ & $\begin{array}{c}\delta\left({ }^{13} \mathrm{C}\right) \\
100 \mathrm{MHz}\end{array}$ & $\begin{array}{c}\mathrm{HMBC} \text { to } \mathrm{C} \\
\text { Optimized to } 8 \mathrm{~Hz}\end{array}$ & $\begin{array}{c}\text { ROESY } \\
\text { Mix }=250 \mathrm{~ms}\end{array}$ \\
\hline 1 & & 169.60 & & \\
\hline 3 & $5.39(\mathrm{br} \mathrm{dd}, 4,2.2)$ & 83.09 & C-12 & $\mathrm{H}-4, \mathrm{H}_{\alpha}-13$ (2.06), $\mathrm{H}_{\beta}-13$ (2.53) \\
\hline 4 & $5.02(d, 2.2)$ & 72.63 & $C-3, C-4 a, C-5, C-13$ & $\mathrm{H}-3, \mathrm{H}-5, \mathrm{H}_{\alpha}-13$ (2.06), $\mathrm{CH}_{3}-14$ \\
\hline $4 a$ & & 130.64 & & \\
\hline 5 & 7.37 (s) & 118.98 & $\begin{array}{l}C-1, C-4, C-4 a^{b}, C-5 a, C-6, \\
C-9^{b}, C-9 a, C-10, C-10 a\end{array}$ & $\mathrm{H}-4, \mathrm{H}-6$ \\
\hline $5 a$ & & 139.33 & & \\
\hline 6 & 7.02 (s) & 98.41 & C-5, C-7, C-8, C-9a, C-9 ${ }^{b}$ & $\mathrm{H}-5, \mathrm{OMe}$ \\
\hline 7 & & 160.88 & & \\
\hline 7-OMe & $3.77(3 \mathrm{H}, \mathrm{s})$ & 55.82 & $\mathrm{C}-7$ & $\mathrm{H}-6$ \\
\hline 8 & & 109.02 & & \\
\hline 9 & & 154.49 & & \\
\hline $9-\mathrm{OH}$ & $9.52(\mathrm{br} \mathrm{s})^{\mathrm{a}}$ & & & \\
\hline $9 a$ & & 108.46 & & \\
\hline 10 & & 161.49 & & \\
\hline $10-\mathrm{OH}$ & $13.75(\mathrm{br} \mathrm{s})^{\mathrm{a}}$ & & & \\
\hline $10 a$ & & 97.43 & & \\
\hline 12 & $4.37(\mathrm{~m})$ & 74.29 & C-4 & $\mathrm{H}_{\beta}-13$ (2.53), $\mathrm{CH}_{3}-14$ \\
\hline 13 & $\begin{array}{l}2.53\left(\mathrm{br} \mathrm{dd}, 13.5,6.2, \mathrm{H}_{\beta}\right) \\
2.06\left(\mathrm{ddd}, 13.5,9,4, \mathrm{H}_{\alpha}\right)\end{array}$ & 40.81 & $\begin{array}{l}\mathrm{C}-3, \mathrm{C}-4 \\
\mathrm{C}-1^{\mathrm{b}}, \mathrm{C}-12, \mathrm{C}-14\end{array}$ & $\begin{array}{l}\mathrm{H}-3, \mathrm{H}-12, \mathrm{H}_{\alpha}-13 \text { (2.06) } \\
\mathrm{H}-4, \mathrm{H}-3, \mathrm{H}_{\beta}-13 \text { (2.53), } \mathrm{CH}_{3}-14\end{array}$ \\
\hline 14 & $1.29(3 \mathrm{H}, \mathrm{d}, 6.5)$ & 21.52 & $\mathrm{C}-12, \mathrm{C}-13$ & $\mathrm{H}-4, \mathrm{H}-12, \mathrm{H}_{\alpha}-13(2.06)$ \\
\hline
\end{tabular}

${ }^{a} \mathrm{D}_{2} \mathrm{O}$ exchangeable. ${ }^{\mathrm{b}}$ Very weak $\mathrm{HMBC}$ correlations. 
observed in a ROESY spectrum, excluded the possibility of a 6,6'-linkage (Fig. 2). Both the 8,8'- and 6,6'bisnaphthopyrones were previously reported as antibacterial compounds, which could respectively be

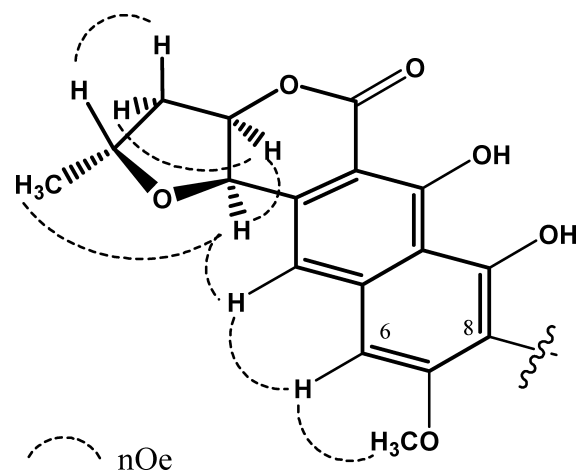

Fig. 2 Stereo-drawing of $\mathbf{1}$ (only half of the structure is shown): selected nOes, observed in a ROESY spectrum, determine the relative configuration of the aliphatic systems and support an 8,8'-linkage between the two halves of the molecule.

No absolute stereochemistry is implied. represented by fungal metabolites, vioxanthin (4) and SC-28763 (5) [11, 12].

Unlike in $\mathbf{3}$ and $\mathbf{4}$, the C-4 in compound $\mathbf{1}$ was an oxygen-attached methine. In a COSY spectrum, the H-4 signal at $\delta 5.02$ was correlated to the methine signal H-3 at 5.39 , which was in turn correlated to the 13-methylene signals at 2.53 and 2.06. These two signals were further coupled to H-12 at $\delta 4.37$, which was then coupled to the 14-methyl signal at 1.29. The molecular formula required that each half-molecule contain an additional ring system to fuse to the naphthopyrone moiety. An HMBC correlation between $\mathrm{H}-12$ at $\delta 4.37$ and $\mathrm{C}-4$ at 72.63 indicated the presence of an ether bridge between C-4 and C-12, which gave rise to a substituted furan ring. In a ROESY spectrum, nuclear Overhauser effects (nOes) were observed between the H-3 and H-4 signals, and between the H-4 and 14methyl signals (Table 1), which defined a cis ring junction between the furan and $\alpha$-pyrone, and synfacial configuration between $\mathrm{H}-4$ and 14-methyl. The relative stereochemistry of compound $\mathbf{1}$ and the selected nOes are shown in Fig. 2. The tetracycle system as described in $\mathbf{1}$ has not been reported in literature.

The molecular formula of lichenicolin B (2) was

Table 2 NMR data for lichenicolin B (2) and luteosporin (6) in DMSO- $d_{6}$

\begin{tabular}{|c|c|c|c|c|c|c|}
\hline \multirow{2}{*}{ No. } & \multirow{2}{*}{$\begin{array}{c}\delta\left({ }^{1} \mathrm{H}\right) \text { of } 2 \\
(400 \mathrm{MHz}, \text { Mult, } J \text { in } \mathrm{Hz})\end{array}$} & \multicolumn{2}{|c|}{$\delta\left({ }^{13} \mathrm{C}\right)(100 \mathrm{MHz})$} & \multirow{2}{*}{ No. } & \multirow{2}{*}{$\delta\left({ }^{1} \mathrm{H}\right)$ of 2} & \multirow{2}{*}{$\delta\left({ }^{13} \mathrm{C}\right)$ of 2} \\
\hline & & 2 & 6 & & & \\
\hline 1 & & 160.22 & 160.8 & $1^{\prime}$ & & 169.15 \\
\hline 3 & $5.26(\mathrm{br} \mathrm{dd}, 4,2)$ & 80.99 & 73.9 & $3^{\prime}$ & $5.37(\mathrm{br} \mathrm{dd}, 4,2)$ & 82.85 \\
\hline 4 & $5.05(d, 2)$ & 72.11 & 35 & $4^{\prime}$ & $4.99(d, 2)$ & 72.73 \\
\hline $4 a$ & & 143.52 & 148.6 & $4 a^{\prime}$ & & 131.18 \\
\hline 5 & 7.63 (s) & 117.57 & 116.5 & $5^{\prime}$ & 7.33 (s) & 118.69 \\
\hline $5 a$ & & 133.93 & 132.2 & $5 a^{\prime}$ & & 139.75 \\
\hline 6 & & 180.75 & 180.0 & $6^{\prime}$ & $6.99,6.98(s)^{b}$ & 98.61 \\
\hline \multirow[t]{2}{*}{7} & & 159.44 & 158.2 & $7^{\prime}$ & & 160.22 \\
\hline & & & & 7'-OMe & $3.80,3.79(3 \mathrm{H}, \mathrm{s})^{\mathrm{b}}$ & 55.92 \\
\hline 8 & & a & 113.9 & $8^{\prime}$ & & 106.89 \\
\hline 9 & & 187.32 & 187.3 & $9^{\prime}$ & & 155.00 \\
\hline $9 a$ & & 115.87 & 114.6 & $9 a^{\prime}$ & & 108.83 \\
\hline 10 & & 161.94 & 161.6 & $10^{\prime}$ & & 161.91 \\
\hline $10 a$ & & 116.76 & 117.8 & $10 a^{\prime}$ & & 97.75 \\
\hline 11 & & & 20.0 & & & \\
\hline 12 & $4.37(\mathrm{~m})$ & 74.97 & & $12^{\prime}$ & $4.37(\mathrm{~m})$ & 74.31 \\
\hline 13 & $\begin{array}{l}2.50\left(\mathrm{~m}, \mathrm{H}_{\beta}\right) \\
1.98\left(\mathrm{ddd}, 13.5,9,4, \mathrm{H}_{\alpha}\right)\end{array}$ & 40.88 & & $13^{\prime}$ & $\begin{array}{l}2.48\left(\mathrm{~m}, \mathrm{H}_{\beta}\right) \\
2.04\left(\mathrm{ddd}, 13.5,9,4, \mathrm{H}_{\alpha}\right)\end{array}$ & 40.88 \\
\hline 14 & $1.28(3 \mathrm{H}, \mathrm{d}, 6.5)$ & 21.53 & & $14^{\prime}$ & $1.29(3 \mathrm{H}, \mathrm{d}, 6.5)$ & 21.46 \\
\hline
\end{tabular}

${ }^{a}$ Not observed due to small quantity. ${ }^{b}$ The cause of double peaks has not been experimentally studied. However, it could be attributed to the presence of diastereomers due to hindered rotation about the $\mathrm{Ar}-\mathrm{Ar}^{\prime}$ bond. 
Table 3 Antimicrobial activity of lichenicolins A (1) and B (2)

\begin{tabular}{|c|c|c|c|c|}
\hline \multirow{2}{*}{ Organism } & \multicolumn{4}{|c|}{$\mathrm{MIC}(\mu \mathrm{g} / \mathrm{ml})^{\mathrm{a}}$} \\
\hline & Penicillin G & Vancomycin & 1 & 2 \\
\hline Bacillus subtilis 327 & $\leqq 0.03$ & 0.25 & 1 & $>64$ \\
\hline Staphylococcus aureus 429 & $\leqq 0.03$ & 1 & 4 & $>64$ \\
\hline Staphylococcus aureus 375 & 0.06 & 0.5 & 2 & $>64$ \\
\hline Staphylococcus aureus 310 (MRSA) & $>64$ & 0.5 & 16 & $>64$ \\
\hline Enterococcus faecalis 431 & 1 & 1 & 8 & $>64$ \\
\hline Enterococcus faecium 379 (VRE) & 16 & $>64$ & 4 & $>64$ \\
\hline Enterococcus faecium 436 & 64 & 1 & 4 & $>64$ \\
\hline Escherichia coli 428 & 32 & $>64$ & 8 & $>64$ \\
\hline Escherichia coli 442 & 16 & $>64$ & 16 & $>64$ \\
\hline Escherichia coli 389 (imp) & 0.5 & 0.5 & 0.25 & $>64$ \\
\hline Enterobacter cloacae 305 & $>64$ & $>64$ & 8 & $>64$ \\
\hline Pseudomonas aeruginosa 432 & $>64$ & $>64$ & $>64$ & $>64$ \\
\hline Candida albicans 54 & $>64$ & $>64$ & $>64$ & $>64$ \\
\hline
\end{tabular}

a Broth dilution method in Mueller-Hinton II, incubated at $35^{\circ} \mathrm{C}$ for 18 hours.

determined by FTICR mass spectrometry to be $\mathrm{C}_{33} \mathrm{H}_{26} \mathrm{O}_{13}$. The UV spectrum of $\mathbf{2}$ showed an absorption shoulder at $\sim 440 \mathrm{~nm}$, which tailed the naphthopyrone absorption maximum at $376 \mathrm{~nm}$. Both the ${ }^{1} \mathrm{H}$ and ${ }^{13} \mathrm{C}$ NMR spectra indicated that 2 was an asymmetric dimer, with half of the molecule being identical to the naphthopyrone monomer in 1 (Table 2). On the basis of ${ }^{13} \mathrm{C}$ NMR signals at $\delta 187.32$ (C-6), 159.47 (C-8), and 180.75 (C-9), and the molecular formula, an hydroxyquinone moiety was proposed for the other half of compound 2. This moiety was found in luteosporin (6) [13], a phospholipase $\mathrm{A}_{2}$ inhibitor isolated from Penicillium chermesinum. The aromatic carbon signals of $\mathbf{2}$ were comparable to those reported for $\mathbf{6}$ (differences $<2 \mathrm{ppm}$ ) with the exception of C-4a (Table 2).

Lichenicolin A (1) showed moderate to good activity against Gram-positive bacteria, including strains of methicillin-resistant Staphylococcus areus (MRSA) and vancomycin-resistant Enterococcus faecium (VRE). For Gram-negative bacteria, compound $\mathbf{1}$ showed activity against Escherichia coli but no activity against Pseudomonas aeruginosa. Compound $\mathbf{1}$ was also inactive against the yeast Candida albicans. Interestingly, lichenicolin A (1) was far less active against $E$. coli widetype strain (\#442) than the imp strain (\#389, strain with increased outer membrane permeability), suggesting poor permeability across the normal Gram-negative outer membrane. Lichenicolin B (2), on the other hand was inactive against all tested organisms. MIC data obtained by the broth dilution method [14] are listed in Table 3.
In a recent publication, pigmentosin A (7), a bisnaphthopyrone compound, was described as a secondary metabolite from a foliose lichen Hypotrachyna immaculata [15]. It will be interesting to investigate whether this compound can be produced by a culturable fungus from $H$. immaculata.

In summary, lichenicolous fungus $L L$-RB0668 was isolated from a processed lichen thallus on a modified Lilly-Barnett solid medium containing L-ribitol. The major antimicrobial lichenicolins A (1) and the minor inactive lichenicolin B (2) were purified from the culture of this organism fermented on a rice-based solid medium. Results obtained from $L L-$ RB0668 and other cultures we studied further demonstrate that lichen-associated fungi are a good resource for new bioactive natural products, and they deserve more attention from screening scientists.

Acknowledgment The authors wish to thank Dr. Xidong Feng for MS measurements, Susan Urbance for assay support, and Drs. Guy Carter, Frank Koehn, and Valerie Bernan for helpful discussions.

\section{References}

1. Crittenden PD, David JD, Hawksworth DL, Campbell PS. Attempted isolation and success in the culturing of a broad spectrum of lichen-forming and lichenicolous fungi. New Phytol 130: 267-297 (1995) 
2. Lawrey J, Diederich P. Lichenicolous fungi: Interaction, evolution, and biodiversity. Bryologist 160: 80-120 (2003)

3. Crittenden PD, Porter N. Lichen-forming fungi: Potential sources of novel metabolites. Trends Biotechnol 9: 409-414 (1991)

4. Seephonkai P, Isaka M, Kittakoop P, Palittapongarnpim P, Kamchonwongpaisan S, Tanticharoen M, Thebtaranonth Y. Evaluation of antimycobacterial, antiplasmodial and cytotoxic activities of preussomerins isolated from the lichenicolous fungus Microsphaeropsis sp. BCC 3050. Planta Medica 68: 45-48 (2002)

5. Takenaka Y, Tanahashi T, Nagakura N, Itoh A, Hamada N. Three isocoumarins and a benzofuran from the cultured lichen mycobionts of Pyrenula sp. Phytochemistry 65: 3119-3123 (2004)

6. Lilly VG, Barnett HL. Physiology of Fungi. McGraw-Hill, New York (1951)

7. Kornerup A, Wanscher JH. Methuen Handbook of Colour, 3rd ed. Eyre Methuen Co., London (1978)

8. Yada H, Sato H, Toshima H, Deura M, Ichihara A. (-)Semivioxanthin, a new abscisic active compound against Hinoki cypress leaves isolated from Cryptosporiopsis abietina. Biosci Biotechnol Biochem 65: 484-486 (2001)

9. Drochner D, Muller M. Total synthesis of $(R)$ - and $(S)$-semivioxanthin. Eur J Org Chem 1: 211-215 (2001)
10. Scudamore KA, Clarke JH, Hetmanski MT. Isolation of Penicillium strains producing ochratoxin A, citrinin, xanthomegnin, viomellein and vioxanthin from stored cereal grains. Lett Appl Microbiol 17: 82-87 (1993)

11. Suzuki K, Nozawa K, Nakajima S, Kawai K. Structure revision of mycotoxin, viriditoxin, and its derivatives. Chem Pharm Bull 38: 3180-3181 (1990)

12. Wang J, Galgoci A, Kodali S, Herath KB, Jayasuriya H, Dorso K, Vicente F, Gonzalez A, Cully D, Bramhill D, Singh S. Discovery of a small molecule that inhibits cell division by blocking FtsZ, a novel therapeutic target of antibiotics. J Biol Chem 278: 44424-44428 (2003)

13. Singh PD, Johnson JH, Aklonis CA, Bush K, Fisher SM, O'Sullivan J. Two new inhibitors of phospholipase A2 produced by Penicillium chermesinum. Taxonomy, fermentation, isolation, structure determination and biological properties. J Antibiot 38: 706-712 (1985)

14. NCCLS. Methods for Dilution Antimicrobial Susceptibility Tests for Bacteria That Grow Aerobically; Approved Standards: M7 A5, Vol. 19. National Committee for Clinical Laboratory Standards, Villanova (2000)

15. Elix JA, Wardlaw JH. Pigmentosin A, a new naphthopyrone from the lichen Hypotrachyna immaculata. Australian J Chem 57: 681-683 (2004) 